\title{
Experimental Wear Modelling of Lifeboat Slipway Launches
}

\author{
B. Thomas, M. Hadfield, S. Austen. \\ Sustainable Product Engineering Research Centre, Bournemouth University, UK \\ Received --/--/-- accepted --/--/--
}

\begin{abstract}
It is necessary to use an inclined slipway to launch lifeboats in locations where there is no natural harbour. Slipway stations consist of an initial roller section followed by an inclined keelway, the lifeboat is released from the top of the slipway and proceeds under its own weight into the water. Contact is between the lifeboat keel and a lined, greased keelway and this that determines the friction along the slipway. This paper describes a bench test methodology to investigate this contact. The selection of a modified TE57 reciprocating tribometer and design of a modified pin on plate arrangement is discussed. A test schedule for both the original nickel/chromium coated steel lining and the new low-friction jute fibre/phenolic resin composite lining is developed to accurately reflect real world conditions including environmental contamination such as seawater or wind-blown sand. Environmentally conscious lubricants including water and bio-greases are investigated and compared for their effects in reducing slipway panel friction and wear. Experimental data is collected to establish wear mechanisms, wear volumes and friction characteristics for a range of lubricants and environmental contaminants for the two most common lifeboat keelway lining materials. Implications of this research for future lifeboat slipway design are discussed.
\end{abstract}

Keywords: Sliding Wear, Lifeboat, Slipway.

\section{Introduction}

The RNLI provides search and rescue (SAR) cover around the coast of the UK and Ireland. In areas where there is no natural harbour, and the ground is not suitable for carriage launched lifeboats the only option allowing a lifeboat to launch in all weather conditions is to use an inclined slipway. The RNLI operates 18 slipway stations in the UK and 2 in the Republic of Ireland, each station is different and each has its own historical launch techniques and slipway geometries though they all follow a common template. The most common configuration is to have an upper section of steel rollers leading onto a smooth, lined, lower section with a typical gradient of 1 in 5 . The boat is launched down the slipway resting on its keel with the plane slipway section coated with grease to reduce friction. The boat is recovered by manoeuvring the keel onto the bottom of the keelway before attaching a winch cable and hauling the boat to the top of the slipway. With the advent of modern, heavier slip launched SAR (search and Rescue) craft such as the 25 tonne Tyne class, introduced in 1982 and its replacement the 30+ tonne Tamar class, being phased in across the country from 2005 the traditional slipway linings of weather treated wood have proved to be unsuitable in many cases. This has led to a number of different slipway linings being adopted including nickel/chromium carbide coated low friction steel and more recently a graphite infused jute fibre/phenolic resin composite material originally developed as a dry or water lubricated marine bearing. The new Tamar class lifeboat will in many cases require significant modifications to, or replacement of existing boathouses and slipways due to its larger size and mass with the graphite infused jute fibre/phenolic resin composite as the preferred lining for all new and reconditioned slipways. The composite has been chosen in

* Corresponding author. Tel. +44 1202524111

E-mail Address: thomasb@bournemouth.ac.uk (B. Thomas) part for its supposed ability to achieve suitably low friction coefficients without the use of grease, which is currently manually applied to the slipway lining before each launch and recovery. The new composite lining is intended to be run either dry, or with freshwater lubrication.

This work is intended towards a method for evaluating the performance of the graphite infused jute fibre/phenolic resin composite slipway lining in comparison to the previously used nickel/chromium carbide coated low friction steel and identify and reduce the causes of high friction and high wear on the lining panels. Suitable lubricants to ensure low friction coefficients are also investigated.

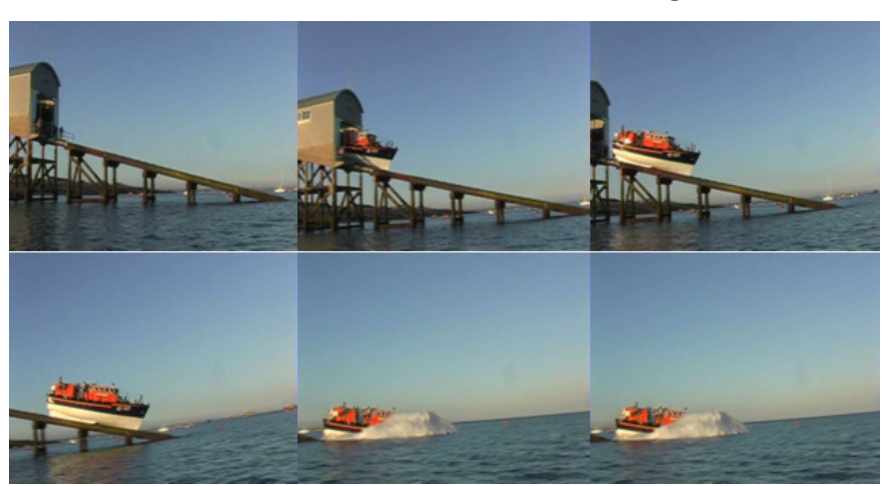

Fig. 1. Typical slipway launch: Tyne class lifeboat at Selsey moves down the plain sliding section of the slipway under its own weight

\section{Current Slipway Lubricants and linings used by the RNLI} Currently, RNLI slipways use a number of slipway linings, lubricants and lifeboats depending on local conditions and historical factors. There are 3 slipway lifeboats used by the RNLI, the Mersey, the Tyne and the recently introduced Tamar. The Mersey is a small, fast lifeboat that can be carriage launched, slipway launched or lie afloat and is currently used 
at just 3 slipway stations in the UK. It was introduced in 1988 and is much lighter than the Tyne and the Tamar at just 13 tonnes. No significant friction and wear issues have been noted with the Mersey due to the lower contact pressures involved and the unique designs of the low number of slipways it uses. The Tyne class slipway launched SAR craft is the main RNLI slipway lifeboat, it is larger and has greater passenger capacity than the Mersey. It was introduced in 1982 and in its current configuration weighs 25 tonnes. It is used at 15 slipway stations around the UK and Ireland. The Tyne class lifeboat is gradually being replaced by the Tamar class; the Tamar is significantly larger, faster and heavier than the Tyne and weighs in at over 30 tonnes. In order to accommodate the larger Tamar class lifeboat many slipways will require modification or a complete rebuild, the two stations currently using the Tamar both have new, specially rebuilt slipways and boathouses. This research focuses on the Tamar class lifeboat and the graphite infused jute fibre/phenolic resin composite material selected as the preferred RNLI slipway lining material.

Currently it is usual to apply lubricant to the lined section of the slipway before launch and recovery to ensure smooth travel. The lubricants used vary somewhat between slipway stations but the most common lubricant is a general purpose marine grease designed to be used in environments where seawater, freshwater or condensation moisture may contaminate the system. Other notable lubricants are a silicon microball infused lubricant, which was originally designed as a cable pulling lubricant and includes silicon microspheres. This lubricant is used at Sennen Cove which has a particularly shallow incline to its launch slipway due to the shallow beach at this location. The new Tamar equipped slipway stations at Tenby and Padstow are also experimenting with freshwater as a lubricant, this is run from pipes at the top of the slipway. The use of a vegetable oil based biogrease in place of the general purpose marine grease has also been proposed in order to reduce the environmental impact of the grease being swept into the sea during launch where it has the potential to bioaccumulate.

There are a number of different slipway linings used on RNLI slipway stations, in most cases these are installed as and when friction or wear problems occur. The traditional slipway lining material is weather treated wood, and it is usual to apply grease to this material. Following the introduction of the heavier Tyne lifeboat the majority of these traditionally lined slipways were re-lined with steel plate featuring a nickel/chromium carbide coating designed for low friction and high wear resistance. As problems with high friction persisted on some slipways, particularly near the water line where grease could be washed away with seawater, a graphite infused jute fibre/phenolic resin composite material was introduced, with the aim of improving the dry running performance in case of the loss of lubricant due to tidal effects. This initially proved very successful, but problems with durability soon led to a change from a $6 \mathrm{~mm}$ section to a thicker $19 \mathrm{~mm}$ section. The graphite infused jute fibre/phenolic resin lining is now the preferred lining for all slipway refurbishments and new slipways as many are re-built to accommodate the Tamar class lifeboat.

Friction problems along the slipway usually manifest during recovery, when the hauling winch loads can increase, in some cases beyond the specification of the winch. This can lead to drastically reduced hauling speeds and shortened winch life. The application of lubricant along the slipway before recovery does reduce this effect but this can be unreliable as inconsistent application and included environmental debris (e.g. wind-blown sand) can make the lubrication regime unpredictable. This has been particularly noted on the recovery slipway at Sennen Cove, where the shallow beach means that sand can be washed along the slipway as the lifeboat is recovered causing variable friction and high wear rates on the lining. High friction on launch presents fewer problems but can result in reduced launch speeds and even seizure. Again, the manual application of lubricant along the slipway before launch is usual and this involves safety issues, particularly in high seas.

Wear on the slipway is also significant. The older treated wood and nickel/chromium carbide coated low friction steel lined slipways experienced relatively light wear during service but the new graphite infused jute fibre/phenolic resin composite has been seen to wear rapidly, and this has led to shorter replacement intervals and reduced efficiency. The wear problem is of particular concern where the composite is used on the new boathouses and slipways for the Tamar class lifeboat at Tenby and Padstow, both these stations have shown some cracking and degrading of the slipway lining during use, despite its recent installation.

\section{Previous work}

There has as yet been very little specific research into the friction and wear along lifeboat slipways though the similar situation of ship launch slipways has been investigated. In order to test the friction characteristics of a ship launch slipway various techniques involving tribometers have also been developed. These generally involve rubbing a sample of the ship keel material (usually steel) against a sample of the slipway liner (usually treated wood) and measuring the friction generated. The tests can also include the lubricants used along the slipway and can be adapted to model environmental effects, e.g. grease degraded in the tidal environment.

Dunn, Kennedy and Tibbs ${ }^{1}$ present a technique for assessing the lubricants and materials used in wooden, ship launch slipways for their friction characteristics using a Denison reciprocating friction machine. The machine uses a plate and pad arrangement to represent the slipway and keel respectively and uses a reciprocating motion to measure the friction at a range of contact pressures, dwell times and velocities. Each test is run until stable friction is achieved, and this is the recorded for the conditions present. Tests are conducted for steel/wood and wood/wood contacts.

Pattison, Dixon and Hodder $^{2}$ describe a test rig developed at Vosper Thornycroft to examine slipway static friction coefficients under different conditions following the launch of the experimental RV Triton. The rig was very simple and consisted of a sample sitting on a plane plate with a separator of plastic sheet or other liners commonly used at VT shipbuilding. The samples were painted with both the low friction anti-fouling paint used on the Triton and also conventional paint for comparison. The static friction coefficient was tested simply by raising the plane plate to an angle where slippage between the sample and the plate occurred. The liner was tested both wet and dry to recreate the conditions at launch where it had become wet after the hull was washed. 
A Previous study ${ }^{3}$ conducted by Newcastle University, commissioned by the RNLI, investigated friction and wear characteristics of various lifeboat keel materials. The aim of this research was to investigate the feasibility of using composite rather than steel keels to reduce the weight of slipway launched lifeboats. Reducing the weight of the lifeboat would consequently reduce the force required to recover the lifeboat onto the slipway and increase the speed. The study compared the friction of conventional keel materials on steel slipways with some composite keel materials, namely glass reinforced Ampreg 26, Kevlar reinforced Ampreg 26, a glass/Kevlar hybrid reinforced Ampreg 26, and a glass reinforced vinyl ester. The study used a pin on disc style tribometer, with the pin representing the steel slipway. Tests were performed dry and with seawater present and the results recorded. Ultimately, though the wear rate proved acceptable in many cases, the friction generated with the new keel materials was too high to be practical and presented greater risk of 'sticking' on the slipway during launch and recovery.

Following this research a second series of tests ${ }^{4}$ were conducted in a similar fashion to investigate a further series of potential keel materials, this time with a number of low friction additives included. Again, it was found that the friction coefficient was too high and that most of the intended low friction additives served to increase rather than decrease the friction. The only material found to perform well in both friction and wear was a glass reinforced phenolic composite and the study concludes by suggesting that this may be a suitable material for further testing, including the possibility of low friction inclusions or coatings to further reduce the friction coefficient. Ultimately, the composite keel concept was abandoned but the promise of phenolic composites was duly noted and influenced the decision to replace the steel slipway lining sections with a graphite infused jute fibre/phenolic resin composite as, and when problems of high friction occurred.

\section{Case Studies}

In order to further investigate the problem a number of slipways around the UK were visited and the slipway surface surveyed for wear patterns. Data from previous slipway trials in which a load cell is placed in line with the winch cable during recovery to monitor the friction encountered on the slipway was collated. This including data from the initial Tamar slipway trials at Tenby $[5,6]$ and Padstow [7], similar data from Bembridge [8,9], Mumbles [10] and Selsey [11,12] is also used. Real life friction and wear on slipways using treated wood, low friction coated steels and jute fibre/phenolic resin composites were examined and compared in this way.

Common wear patterns specific to all the jute fibre/phenolic resin composite lined slipways were observed in each of the slipways surveyed where fitted. This wear could be separated into four main types: ploughing wear due to raised sections on the lifeboat keel, delamination wear and cracking at the ends and edges of the composite panels. There was no significant material transfer between the lifeboat keel and the slipway lining observed.

\section{Longitudinal Panel Edge Wear:}

It is observed that significant wear occurs in the area where the wear track passes over the panel end edge as shown in fig. ? below. It is theorised that this is likely to be due to the effects of geometric stress concentrations. To examine this the panels are modelled under normal loading using FEA techniques, the results indicate that the areas of increased stress correlate well with the wear in the real world slipway as shown below in fig. ?.

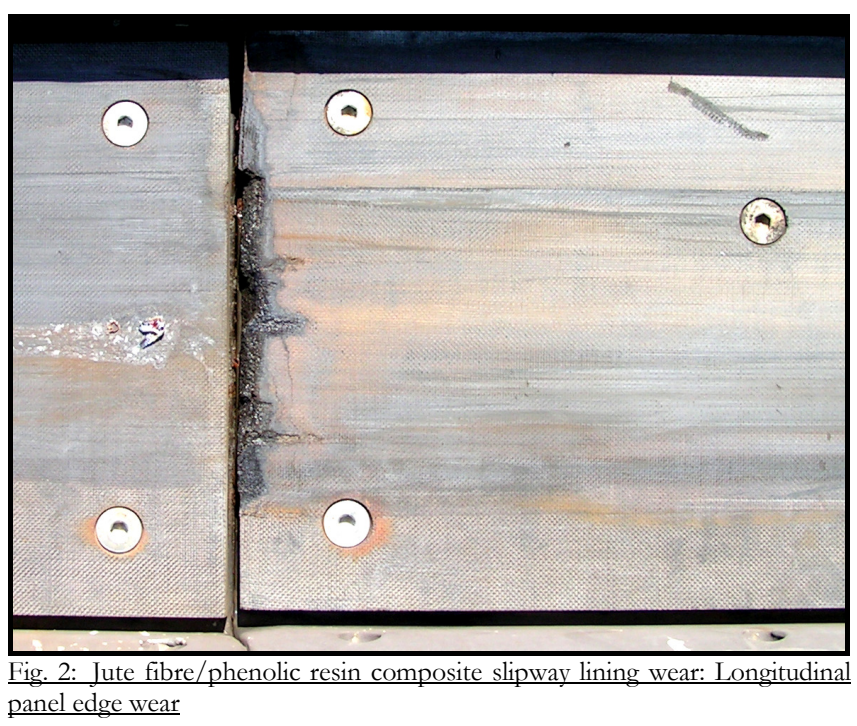

In future work it is intended to combine the wear coefficient results from the tribometer contact force tests with the FEA model in order to more accurately simulate the wear at these geometric concentrations.

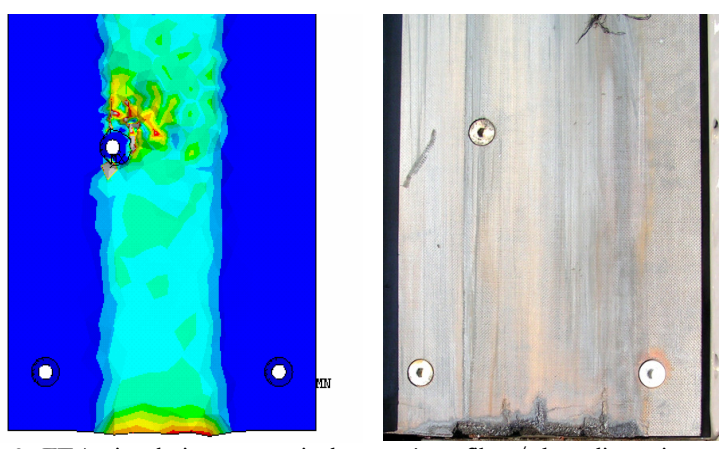

Fig. 3. FEA simulation vs. typical worn jute fibre/phenolic resin composite lining section from Tenby slipway

\section{Panel Delamination Wear:}

A few isolated incidents of panel delamination were observed. These tended to occur in areas where water absorbtion had led to swelling and the resulting panel misalignment and higher contact stresses. 


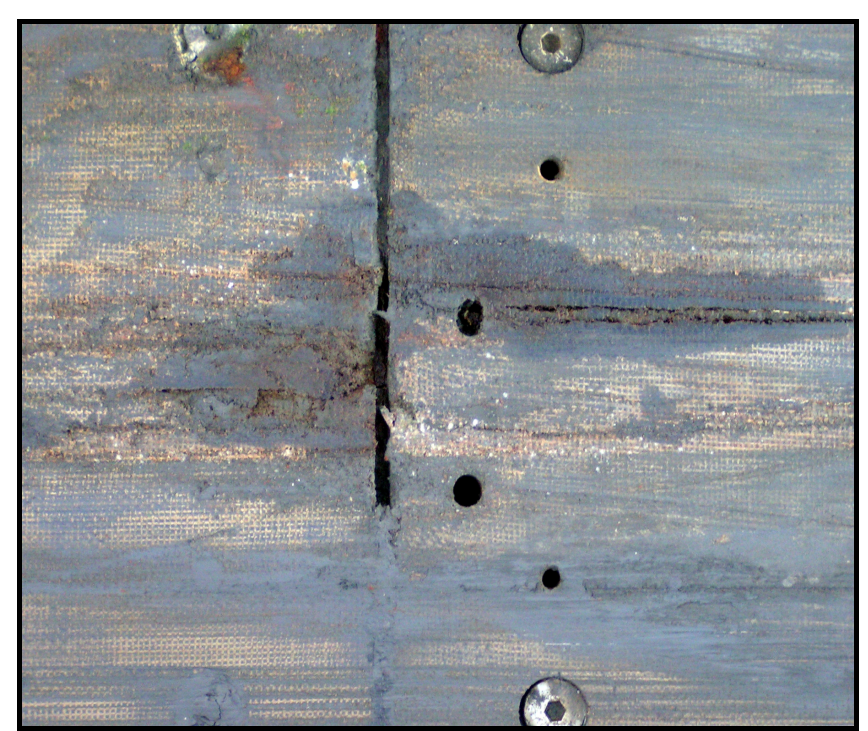

Fig. 4. Jute fibre/phenolic resin composite slipway lining wear regimes: Delamination wear

\section{Keel Locating Area Panel Side Wear:}

Wear at the edges of the slipway lining sections is observed at the region where the lifeboat keel initially mounts the slipway during recovery. From observation it is seen that this is due to the impact of the keel on the slipway panels, particularly when the keel slides from the surrounding slipway superstructure into the keelway to locate before hauling begins rather than sliding wear effects.

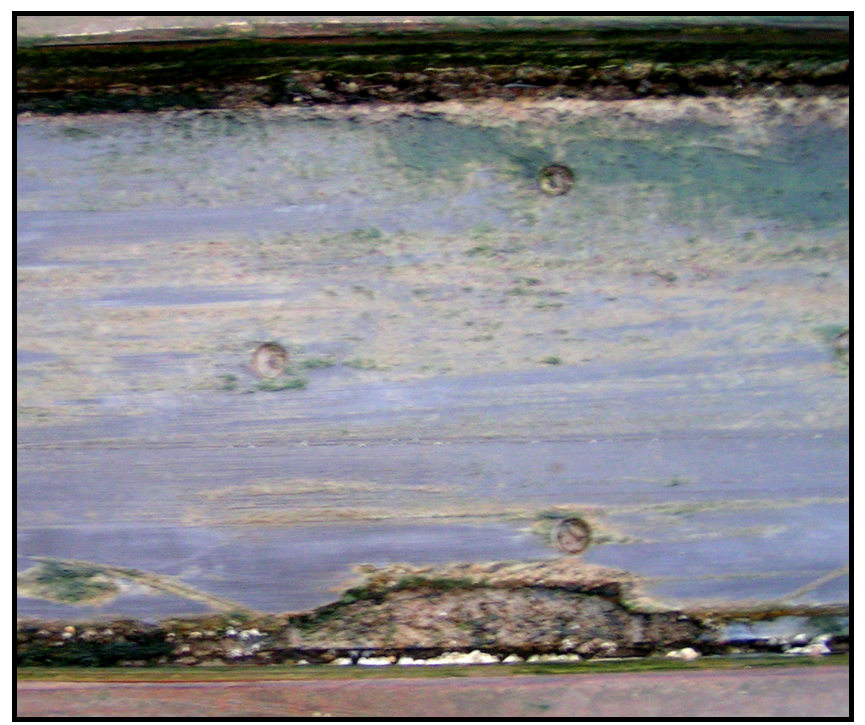

Fig. 5. Jute fibre/phenolic resin composite slipway lining wear regimes: Keel locating area panel side wear

\section{Gouging Wear:}

This is thought to be caused by either damage to the lifeboat keel to generate a protruding section, or the presence of 3 body wear due to a foreign body becoming trapped between the keel and the slipway lining.

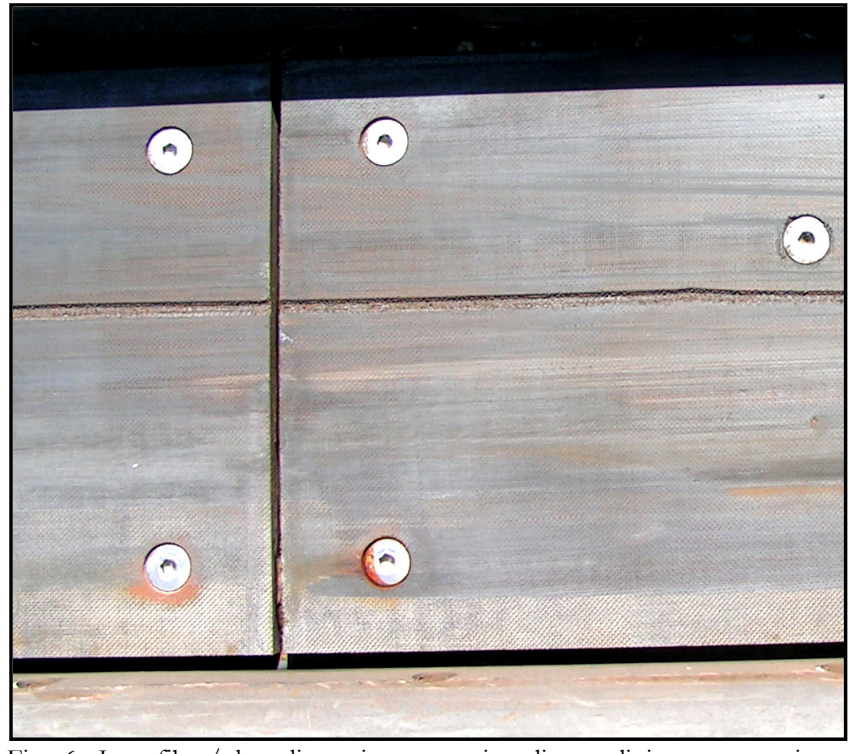

Fig. 6. Jute fibre/phenolic resin composite slipway lining wear regimes: Gouging wear

\section{Summary}

Of these wear regimes the dominant cause of slipway lining failure is the cracking and material loss at the end of each composite section. This can progress to the fixing bolts and can cause the slipway lining panel to separate from the keelway. Gouging wear from a raised section of the lifeboat keel, while removing a significant amount of material from the lining panels, has not been observed to cause sufficient damage to separate the panels from the keelway. Subsequent investigation has revealed that the keel of the initial test Tamar used on both the Tenby and Padstow slipway trials was damaged and this accounts for the similar gouging wear seen on both these slipways. Cracking at the edges of the composite panels is observed at the lower end of the slipway where the lifeboat keel can impact the lining under the action of waves. The edges of the lining panels do not bear any weight during normal launch and recovery. Delamination wear was observed only in a very few isolated areas where swelling through water absorbtion or misalignment had resulted in raised areas of lining which were under far higher pressure than intended. Because of the very few examples of delamination wear observed at limited damage in each case this is not considered to be a primary wear mechanism. Panel misalignment at areas of high wear was observed suggesting that this could be a major contributor to wear.

\section{Friction Theory}

Standard friction theory relates friction to contact pressure using the friction coefficient $\mu(\mathbf{F}=\mu \mathbf{R})$. The overall friction coefficient can be considered to be the sum of the friction coefficients from the various common friction mechanisms, i.e:

$$
\mu_{\text {overall }}=\mu_{\text {adhesion }}+\mu_{\text {deformation }}+\mu_{\text {ploughing }[13]}
$$

For polymers in dry sliding conditions, each of these contributions can be assessed using the following formulae:

When a smooth polymer slides against a relatively smooth, rigid counterface as in this case, the contribution of 
deformation friction becomes negligible and the primary component of friction is adhesion between the two surfaces [14]. Due to the primarily elastic contact the situation approximates to the contact of a single giant asperity so that:

$$
\mu_{\text {adh }} \propto W^{-1 / 3}
$$

Due to the coplanar nature of the contact in this case the friction due to deformation is negligible and only likely to comprise a significant fraction of the overall friction observed at points when the contact moves away from the coplanar regime.

An even ploughing scar from a raised section on the keel is noted on the composite panel slipways of Tenby and Padstow. From inspection the scar is determined to be roughly conical in profile and so will contribute to the friction coefficient:

$$
\mu_{\text {plough }}=(2 / \pi) \cot \alpha
$$

Where $\alpha$ is the apex semi-angle of a conical asperity.

From measurements of the slipway scar the theoretical ploughing friction coefficient for this contact is 0.408. Slipway trials indicate that this is seldom reached in normal operation so it can be assumed that ploughing friction is an infrequent phenomenon. In fact, subsequent investigation shows that the keel of the initial Tamar prototype was damaged forming a protruding section of the right size and shape to generate the wear scars seen after the initial slipway trials at Tenby and Padstow, this may have generated the stick-slip phenomenon on recovery associated with high friction coefficients. The lifeboats currently in use at these locations now have smoother keels and it is evident that the ploughing wear initially observed was an isolated incident related solely to the damaged keel of the Tamar prototype.

\section{Wear Theory}

Wear of polymers is usually a combination of fatigue and abrasion, in relatively high modulus materials like the graphite infused jute fibre/phenolic resin composite slipway lining abrasive wear tends to dominate. Wear on the slipway panels can be expressed as a function of the contact load and sliding distance to generate a wear coefficient.

\section{Dimensional Wear Coefficient:}

$$
\mathbf{K}=\mathbf{Q} \mathbf{P}_{\mathbf{y}} / \mathbf{L W}
$$

$$
\begin{aligned}
& \mathbf{K}=\text { Dimensional Wear Coefficient }\left(\mathrm{mm}^{3} / \mathrm{Nm}\right) \\
& \mathbf{Q}=\text { Wear volume }\left(\mathrm{mm}^{3}\right) \\
& \mathbf{L}=\text { Sliding distance }(\mathrm{m}) \\
& \mathbf{W}=\text { Contact load }(\mathrm{N})
\end{aligned}
$$

The wear coefficient is used to compare the performance of the slipway linings and lubrication regimes.

\section{Experimental methodology: TE57}

An experimental methodology drawing on the previous work mentioned above is devised. It is proposed to use a Plint TE57 reciprocating friction machine to evaluate the performance of slipway lining materials in a similar fashion to Dunn, Kennedy and Tibbs ${ }^{1}$.

The TE57 is a tribometer designed to provide an accelerated method for assessing friction and wear between pin and plate materials under various tribological conditions. It was developed and subsequently modified to include a pressure chamber and a greater range of lubricant regime testing by Plint Tribology. A schematic is shown in Fig. 1. A pin, actuated by a motor reciprocates at up to $50 \mathrm{~Hz}$ with a stroke length of up to $5 \mathrm{~mm}$. The specimen is attached below the pin and a contact force of up to $50 \mathrm{~N}$ is applied using a spring loaded lever arrangement. The specimen sits in a bath that can be used to hold the lubricant when testing lubricated friction scenarios. The friction force on the sample is recorded using a force transducer in series with the horizontal actuating ram. The signal from the transducer is recorded throughout the stroke and in this way the friction coefficient between the pin and specimen can be calculated. The velocity of the motion and test duration is set by an electronic controller.

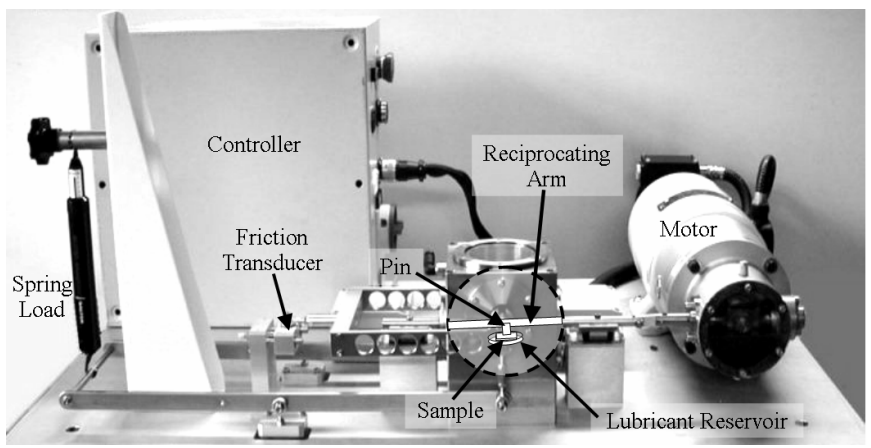

Fig. 7: Plint TE57 Reciprocating Tribometer Schematic

\section{Sample Preparation}

The existing TE57 tribometer is set up in a cylinder on plate or ball on plate arrangement. This is unsuitable in this case as contact is evenly distributed along the keel of the lifeboat and is a coplanar contact. The contact is also distributed over a constant area during launch and recovery making the sphere and barrel on plane arrangements unsuitable as these would involve the contact area growing as the pin wears. Pin/sample alignment issues in the past have also necessitated the use of corrective calculations for contact pressures, friction and wear rates. A modified test rig is proposed to more closely model the real world situation using a coplanar contact and a self levelling pin to ensure evenly distributed contact pressures.

This is accomplished by using a pin with a conical section at the top with a rubber pad between it and the pin holder and an 'O' ring holding it in position in the holder. This arrangement allows the pin to self level as the sample reciprocates, maintaining coplanar contact. The modified design is shown below in Fig. 5. 

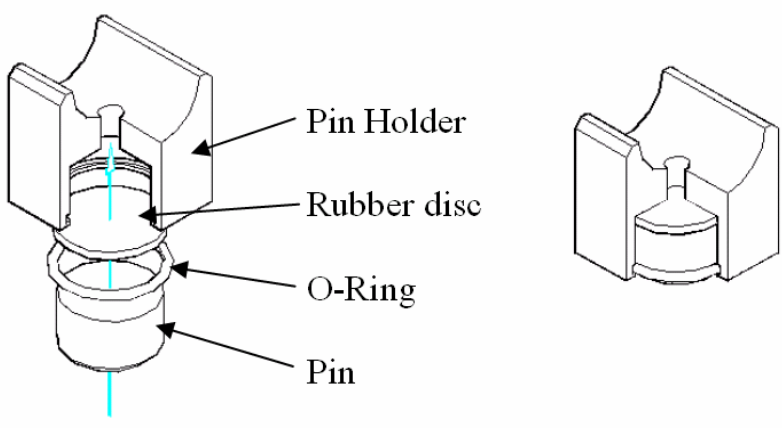

Fig. 8. TE57 Modified Pin Design

For these tests pin diameter, frequency and stroke must all be calculated to mirror the real life situation. Using the Tamar lifeboat mass of 30 tonnes a keel contact area of $1.95 \mathrm{~m}^{2}$ and a typical slipway angle of $11.4^{\circ}(1$ in 5$)$ the contact pressure is calculated as $148 \mathrm{kPa} / \mathrm{m}^{2}$. The TE57 can apply a contact force of 0 to $50 \mathrm{~N}$ so the pin contact area will be calculated to deliver a contact pressure of $148 \mathrm{kPa} / \mathrm{m} 2$ within this range. Using a pin diameter of $10 \mathrm{~mm}$ a force of $11.6 \mathrm{~N}$ will deliver $148 \mathrm{kPa} / \mathrm{m}^{2}$. The stroke is set to its maximum value of $5 \mathrm{~mm}$ so as to better model the slipway situation. The reciprocating frequencies used are derived from the launch and recovery velocities. From previous experience the majority of high fiction and wear events occur during the recovery of the lifeboat to the top of the slipway, and this manifests as very slow recovery speed and possible damage to the winch. Because of this it is decided to concentrate on this aspect for the tribometer tests. For the recovery scenario the frequency is based on the RNLI specified recommended winch line speed of $15 \mathrm{~m} / \mathrm{min}$. The TE57 is set so that the rms average speed matches this, corresponding to a frequency of $25 \mathrm{~Hz}$

\section{Tests Schedule}

Tests are conducted in two stages, first a series of long tests are performed to mimic the wear generated on the slipway lining after the expected total sliding distance during the scheduled 2 year lifespan of the slipway lining. This is calculated as 50 launches/year, with both launch and recovery this equates to two passes over the slipway lining per launch, the average length of slipway lining contacted by the keel during launch is $45 \mathrm{~m}$ so this equates to a total sliding distance during the expected 2 year life of the slipway lining panels of $9 \mathrm{~km}$. On the TE57 machine at a frequency of $25 \mathrm{~Hz}$ this equates to a 10 hour continuous test. These tests are conducted for a number of common and proposed lubrication scenarios as detailed below in table \#. Friction is recorded using the in-built force transducer at intervals of 10 seconds and wear is examined after the tests conclusion using optical inferometry techniques to determine wear scar depth and wear volume, and thus the wear coefficient for the tested conditions.

Secondly, a series of shorter tests are run for varying lubrication regimes and contact pressures in order to investigate the effects on the friction coefficient. These tests are run until stable friction is achieved. The aim of the tests is to check the veracity of the First Law of Friction in each case, and to compare the lubrication regimes at varying normal loads such as might be experienced when the slipway lining is uneven, damaged or misaligned, or the lifeboat keel does not sit flat on the slipway i.e. during the initial stages of recovery from the water, due to tilting during launch or recovery or due to unevenness in the lifeboat keel.

Tests are performed under a number of lubrication regimes to provide a broad picture of the real world case. The lubricants tested are chosen to encompass those currently in use on existing slipways, i.e. no lubricant (dry), marine grease as used on the majority of slipways of both lining materials, a silicon microsphere infused lubricant as used at Sennen Cove and proposed for possible use elsewhere, seawater and freshwater. In addition, two biodegradable greases are selected in order to evaluate their feasibility for slipway use, this would reduce the environmental impact of the accumulated grease around the end of the slipway.

Also tested are scenarios where the lubricant is contaminated with sand, this has been proposed as a possible reason for the increased friction during recovery at Sennen Cove; a seawater/sand mix, a freshwater/sand mix and a marine grease/sand mix are tested. Finally, a marine grease/seawater mix is also tested to investigate the case near the bottom of the slipway where mixing may have occurred.

\section{Post Test Analysis:}

Following the tests the samples are inspected using light microscope and surface profile inferometry techniques to examine the wear scar area. Due to lubricant absorption by the composite and the low wear rates experienced in some cases it is difficult to assess the wear volume using solely mass loss, profile inferometry is used here to assess the wear scar volume and determine the wear coefficient.

\section{Contact Force Tests:}

Tests are conducted on the jute fibre/phenolic resin composite at contact forces of $5,10,15,20,25,30,35,40,45$ and $50 \mathrm{~N}$ for the following lubrication regimes:

\begin{tabular}{|l|l||l|l|}
\hline ID & Lubricant & ID & Lubricant \\
\hline C1-10 & Dry & C41-50 & Marine Grease/Water \\
\hline C11-20 & Seawater & C51-60 & Silicon Microball Lub. \\
\hline C21-30 & Freshwater & C61-70 & Biogrease 1 \\
\hline C31-40 & Marine Grease & C71-80 & Biogrease 2 \\
\hline
\end{tabular}

Table. 1. Contact Force Tests

In addition the same test sequence is performed using the previously used low friction coated steel slipway material under dry and marine grease lubricated sliding conditions (test ID C81-2) for comparison.

\section{Wear Tests:}

Tests are conducted for the following lubrication regimes for a duration of 10 hours in order to simulate the total sliding experienced by the lining during its expected uselife of 2 years.

\begin{tabular}{|c|l||c|l|}
\hline ID & Lubricant & ID & Lubricant \\
\hline W1 & Dry & W7 & Biogrease 2 \\
\hline W2 & Seawater & W8 & Dry/Sand \\
\hline W3 & Freshwater & W9 & Seawater/Sand \\
\hline W4 & Marine Grease & W10 & Freshwater/Sand \\
\hline
\end{tabular}




\begin{tabular}{|c|l||c|l|}
\hline W5 & Silicon Microball Lub. & W11 & Marine Grease/Sand \\
\hline W6 & Biogrease 1 & W12 & Silicon Microball/Sand \\
\hline
\end{tabular}

Table. \#. Wear Tests

\section{Test Procedure}

Suitable pins and specimens are prepared to represent the keel and the slipway lining respectively. The pin is S275 J2G3 steel as used on the Tamar class keel while specimens are made from the graphite infused jute fibre/phenolic resin composite that is the preferred slipway lining material for the RNLI and the low friction coated steel it replaces. Where lubricated conditions are to be tested the specimen sits in a bath of lubricant throughout the test.

\section{Friction Coefficient}

A typical 1 in 5 RNLI slipway with a Tamar class lifeboat requires a friction coefficient of less than 0.3 for the boat to progress down the slipway under its own weight and to ensure consistently low winch loadings this should be in the region of 0.15 . For comparison, trials of the greased low friction coated steel on real world slipways have often approached a friction coefficient of 0.2

\section{Contact Force Tests - Results:}

The results from the contact force tests are shown in figure \# below. These results show a good correlation with the proportionality of $\mathrm{W}^{-1 / 3}$ which would indicate that the adhesive friction is the dominant regime. It is also noticeable that the addition of lubricants significantly reduces the friction force encountered, particularly at the most likely contact force region of $10-25 \mathrm{~N}$. This would seem to indicate that the presence of a lubricant is indeed beneficial to the friction coefficient, though the benefits of seawater or freshwater lubrication are low. The dominant lubricated friction regime for all lubricants would appear to be boundary lubrication as the friction coefficient remains constant for varying loads, separate experiments have also confirmed this to be the case at varying speeds. Also of note is the marked difference between the marine grease and the marine grease/seawater lubricated cases. This indicates that the friction coefficient can indeed increase markedly in this region as indicated by real world examples. With the jute/phenolic composite the friction coefficient still remains within acceptable limits however.

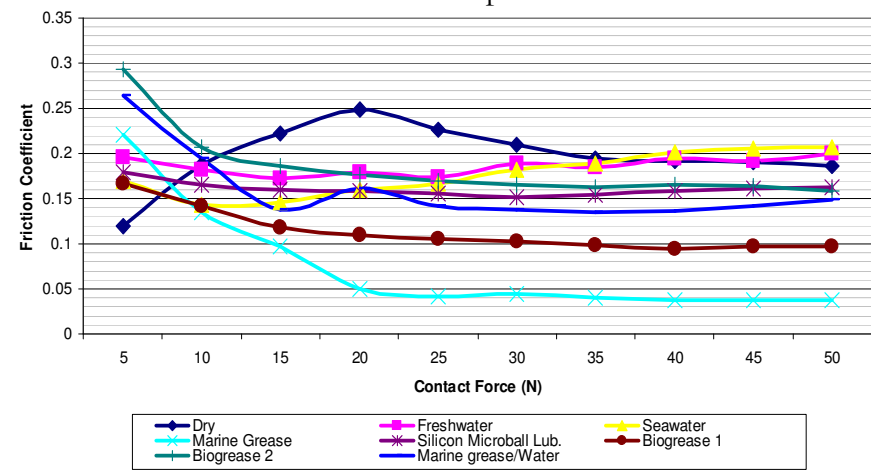

Fig. 9. TE57 Feroform F21 Fiction Coefficient vs. Contact Pressure

Comparing the new jute/phenolic composite slipway lining material with the previously used low friction coated steel shows the dry sliding friction coefficient for the composite is on average just $27 \%$ of the coated steel result. Even when the steel lining is greased as intended the jute/phenolic composite still performs well in comparison and when the composite is run greased the friction coefficient is far lower. This significant reduction in friction would seem to justify the introduction of the new slipway lining material and highlight the dangers of sections of steel lined slipways losing grease to approach a dry sliding scenario.

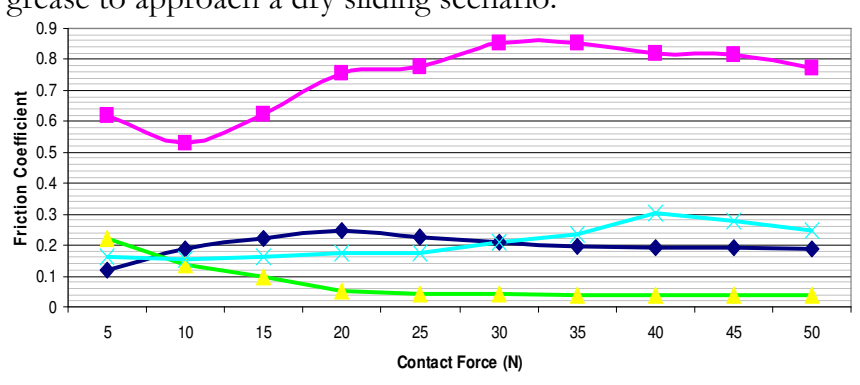

$\rightarrow$-graphite infused jute fibre/phenolic resin composite
- -nickel/chromium carbide coated low friction steel
-- graphite infused jute fibre/phenolic resin composite/Marine grease
$-\quad$ nickel/chromium carbide coated low friction steel/Marine grease

Fig. 10. TE57 Feroform F21 vs. Colmonoy 88 Fiction Coefficient at various Contact Pressures

\section{Wear Tests - Results:}

The results from the wear tests conducted are shown below in figs. \#\#\#. Shown are the average friction coefficient recorded during the duration of the 10 hour test, the Standard Deviation of the friction coefficient during the test and the dimensional wear coefficient for the samples as determined using light inferometry techniques to investigate the wear scar volume after the test.

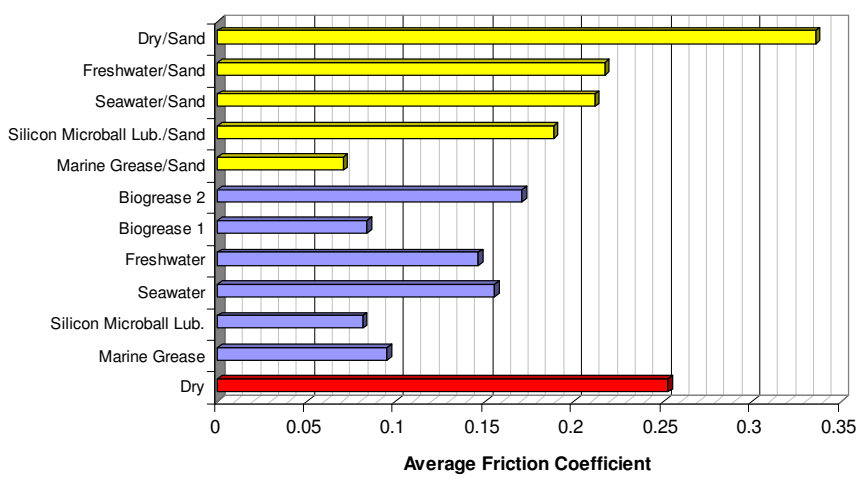

Fig. 11. TE57 Feroform F21 Friction Coefficient vs. Lubricant Regime 10hrs $\underline{\text { Test }}$

The results from these tests indicate that the jute/phenolic composite is able to meet the upper limit of this specification even under dry conditions and, under lubrication will meet the preferred target of $\mu=0.15$. In fact, the composite will only exceed the specification when contaminated with sand. Experience from Sennen Cove and other slipway stations indicates that this condition is usually encountered at the base of a shallow slipway, where the sand is washed onto the slipway lining and usually remains mixed with seawater. Under these mixed conditions the friction coefficient again remains below the upper limit of the specification which would indicate that the presence of sand on the slipway should not present a serious hazard to the progress of the lifeboat into the sea. 


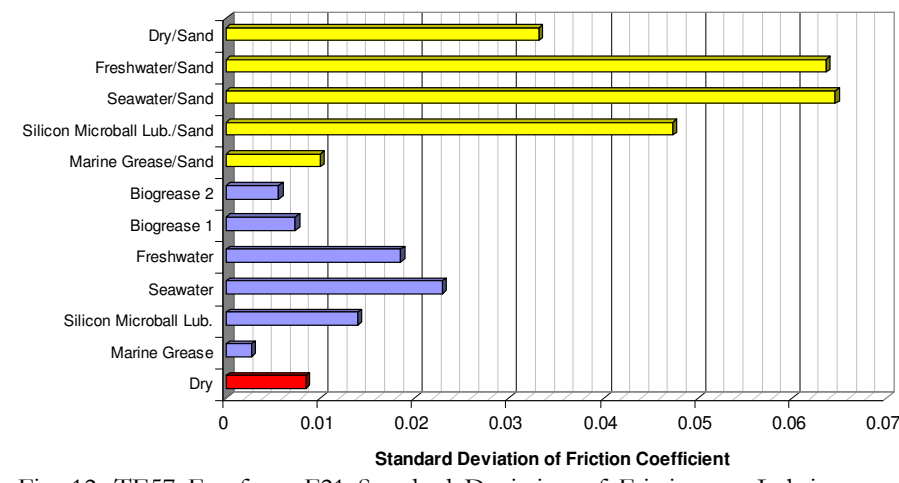

Fig. 12. TE57 Feroform F21 Standard Deviation of Friction vs. Lubricant Regime 10hrs Test

The standard deviation of friction results are shown above in fig. \#. This can be seen as an indicator of the variability of the friction from the average result under the different lubrication regimes tested. The results show that for lubrication under normal conditions the friction variability is generally low, exceptions to this rule are the seawater and freshwater lubricated cases and the silicon microball lubricant. In each case tested the lubrication regime is found to be boundary lubrication, and this is shown by the even friction coefficients seen at varying contact loads during the contact force tests. If the friction was found to change with increasing contact force it would indicate a change in the lubricant regime but this is not found to be the case.

In the seawater and freshwater cases this is likely to be due to an occasional breakdown in the lubrication regime, allowing some unlubricated asperity contact. This effect is more prevalent in the water lubricated cases due to its relatively low viscosity.

The friction variability increases significantly with the addition of sand contamination as would be expected due to the changing geometry and placement of the sand particles in the contact zone, as mentioned above however, the addition of a lubricant does mitigate this effect and the average friction still remains below the upper limit of the RNLI specification for all but the dry/sand case.

\section{Wear Coefficient}

The wear coefficient recorded for the same experiments is shown below in fig\#\#. As can be seen, the wear rates are uniformly low under ideal conditions and would present no particular problems during the expected use-life of the lining. However, as soon as environmental contamination in the form of sand is introduced, the wear rates increase dramatically and could generate significant problems where this situation is commonly encountered.

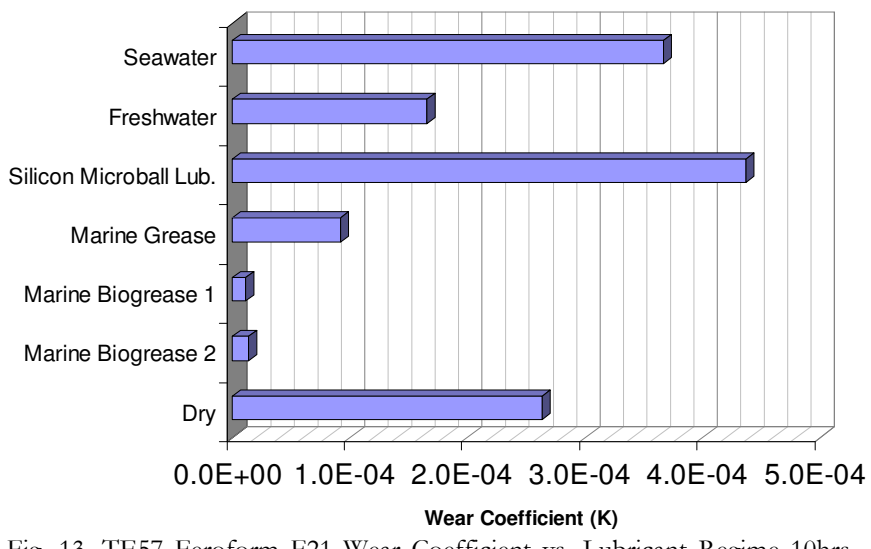

Fig. 13. TE57 Feroform F21 Wear Coefficient vs. Lubricant Regime 10hrs Test

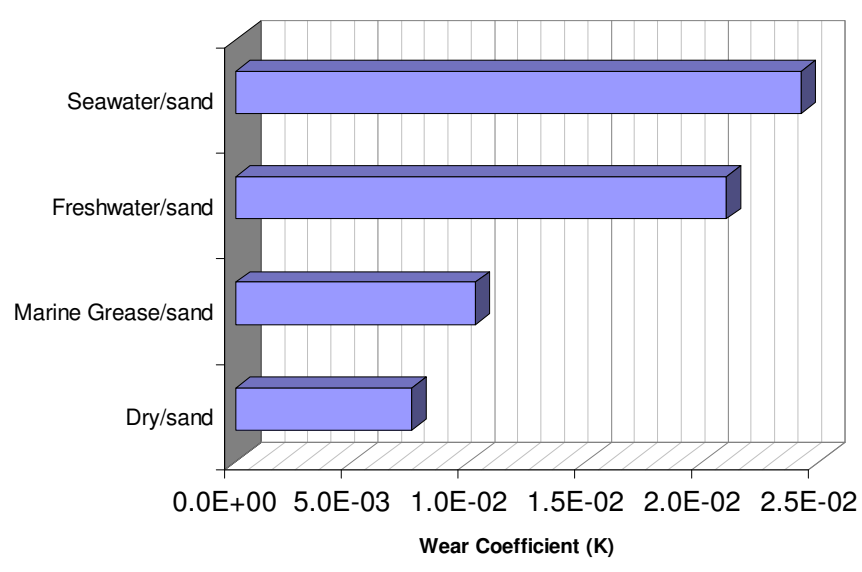

Fig. 14. TE57 Feroform F21 Wear Coefficient vs. Lubricant Regime 10hrs Test

\section{Concluding remarks}

This study shows that the selection of a jute/phenolic composite to replace the existing low friction coated steel slipway lining presents significant benefits in reducing the friction coefficient along the slipway. This is particularly true in the unlubricated case where the friction coefficient of the jute/phenolic composite remains under the upper friction coefficient limit of 0.3 whereas the low friction steel has an average friction coefficient of 0.74 - far too high for reliable launch or recovery. It is likely given this research that the majority of cases where very high friction and winch loading was encountered in the past using the low friction coated steel are due to a breakdown in the lubrication so that the friction coefficient will increase from the average of 0.27 for boundary marine grease lubrication to the unlubricated case of $\mu=0.74$. Using the jute epoxy composite the range between the marine grease lubricated case and the unlubricated case is $\mu=0.07-0.19$ according to the contact tests and $\mu=0.09-0.252$ according to the extended tests which will allow reliable launch conditions even if the lubrication regime should break down.

The use of lubricants with the jute/phenolic composite to further reduce friction to the ideal level of $\mu \approx$ 0.15 is possible with all lubricants tested approaching this value. However the use of marine grease, the silicon microball lubricant and the biogreases still presents the problem of applying the grease to the slipway manually in high seas. The 
use of seawater or freshwater could circumvent this problem by using water jets mounted at the top of the slipway to run water along it, this would also help to ensure consistent friction with the case near the bottom of the slipway where seawater is present.

Environmental impacts from the use of lubricants near an open environment can be reduced in two ways: firstly the lubricants themselves could be substituted with biodegradeable greases such as Biogrease \#1 and 2 tested here. These have been shown to be effective in reducing the friction from the dry sliding case and would reduce the impact of the grease being washed into the sea on launch. Of the two biogreases tested, biogrease \#1 is the most effective, exhibiting lower wear and friction than biogrease \#2. The second approach would be to switch to a seawater or freshwater lubrication system; this would have negligible environmental impact and would also remove the danger of manually applying the grease to the slipway in hazardous conditions.

The use of the silicon microball lubricant is shown to be effective but doubts exist as to its suitability in this case. This is primarily due to the dangers of microball build up with repeated use, the longer wear tests revealed a hard residue of dried lubricant and microballs around the wear scar and this could present problems if allowed to build up in the full size case, this would be a particular problem if the lubricant were left on the slipway to dry during the sometimes long intervals between launch and recovery. The silicon microballs also present an environmental impact if they are allowed to accumulate at the bottom of the slipway. The performance of the lubricant was good, but was matched by the other lubricants tested leaving little reason to favour its use.

The wear rates for all uncontaminated lubricant regimes are shown to be low, and this would indicate that this is not a particularly important variable in selecting a suitable lubricant for real world use. When sand contamination is introduced the wear rates increase dramatically though would still present little real problem during the 2 year scheduled lifespan of the lining. Subsequent research has shown that slipway wear is predominantly caused by panel misalignment and keel impacts during the locating of the keel to the keelway during the initial stages of the recovery of the lifeboat. One possible solution to the presence of sand along the slipway is to use a seawater or freshwater lubrication system as described above, this would run water down the slipway prior and during launch and recovery which would wash away any sand or other environmental debris present.

\section{Future Work}

Further study into the friction and wear of slipway lining materials is to be completed but the next stage of research is to investigate the contributions of keel impact and slipway panel misalignment to the friction and wear conditions on the slipway. Contact tests show that the friction force is proportional to the contact stress and this is increased in regions of panel misalignment where the contact moves away from the parallel plane on plane case. It is intended that combining the results from the two aspects of this research will present a comprehensive picture of the causes of real world friction and wear on lifeboat slipways.

\section{Acknowledgements}

The Authors would like to thank the EPSRC and the RNLI for co-funding this work, and in particular the RNLI for providing support and information throughout the research.

\section{References}

1. Dunn, T, Kennedy, A and Tibbs, J: 'Launching in the 21 st Century'. Drydocks Launching and Shiplift, London, UK: 87-91. Royal Institute of Naval Achitects. (2003)

2. Pattison, N, Dixon, $\mathbf{M}$ and Hodder, C: 'Launching and Docking: Experiences at VT Shipbuilding'. Drydocks Launching and Shiplift, London, UK: 35-40. Royal Institute of Naval Achitects. (2003)

3. Bull, S.J. and Birmingham, R: 'Slip Launched Lifeboats: Materials for Keel and Keelway'. A study for the RNLI (1997)

4. Bull, S.J, Horvathova, K, McNaught, $R$ and Birmingham, R: 'Friction and Wear of alternative Composite Keels for Slip Launched Lifeboats'. A study for the RNLI (1999)

5. Clayton Engineering: 'Trial Results: New Tenby Boathouse Winch Instrumented Line Pulls - 10/05/05'. A study for the RNLI (2005)

6. Clayton Engineering: '2 ${ }^{\text {nd }}$ Instrumented Line Pull Trial Results: New Tenby Boathouse Winch - 10/08/07'. A study for the RNLI (2007)

7. Clayton Engineering: 'Trial Results: New Padstow Boathouse Winch Instrumented Line Pulls - 06/06/06'. A study for the RNLI (2006)

8. RNLI: 'Bembridge Slipway Trial: April 1999'. Internal RNLI Document (1999)

9. RNLI: 'Bembridge Slipway Trial: October 2001'. Internal RNLI Document (2001)

10. Clayton Engineering: 'Instrumented Line Pull Trial Results: Mumbles Boathouse Winch - 10/08/07'. A study for the RNLI (2007)

11. RNLI: 'Selsey Slipway Winch Load \& Keelway Lining Trial Report: March 2002'. Internal RNLI Document (2002)

12. RNLI: 'Selsey Slipway Trial: November 2002'. Internal RNLI Document (2002)

13. Bowden F.P. and Tabor, D: 'The Friction and Lubrication of Solids, Part II', Clarenden Press (1964)

14. Hutchings, I: 'Tribology - Friction and Wear of Engineering Materials', Arnold (1992), p54-5 
15. Bhusan, B: 'Principles and Applications of Tribology', Wiley (1999)

16. Archard, J.F: 'Contact and Rubbing of Flat Surfaces'. Journal of Applied Physics., 24, p981-8 (1953) 